\title{
Sulfur dioxide measurements in the lower, middle and upper troposphere: Deployment of an aircraft-based chemical ionization mass spectrometer with permanent in-flight calibration
}

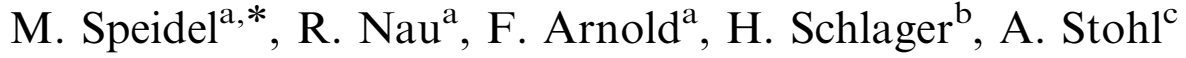 \\ ${ }^{a}$ Max-Planck-Institute for Nuclear Physics, Atmospheric Physics Division, Saupfercheckweg 1, 69117 Heidelberg, Germany \\ ${ }^{\mathrm{b}}$ Deutsches Zentrum für Luft- und Raumfahrt (DLR), Institut für Physik der Atmosphäre, Oberpfaffenhofen, Germany \\ ${ }^{\mathrm{c}}$ Norwegian Institute for Air Research (NILU), P.O. Box 100, 2027 Kjeller, Norway
}

Received 3 March 2006; received in revised form 26 July 2006; accepted 28 July 2006

\begin{abstract}
Measurements of atmospheric $\mathrm{SO}_{2}$ have been made at altitudes between ground level and $12 \mathrm{~km}$ in the lower, middle and upper troposphere. The measurements were carried out within the framework of the ITOP (Intercontinental Transport of Ozone and Precursors) campaign in summer 2004 above Europe and the Eastern Atlantic. They were made using a novel very sensitive and fast-response aircraft-based ion trap CIMS instrument (ITCIMS; CIMS = chemical ionization mass spectrometry), which was continuously calibrated using isotopically labelled $\mathrm{SO}_{2}$. During a total of eight flights of the research aircraft FALCON (DLR) air masses of different origin and different degree of pollution, indicated by measured elevated atmospheric $\mathrm{SO}_{2}$ mole fractions, were intercepted. Often elevated concentrations of $\mathrm{SO}_{2}$, which stemmed from North America were observed over Europe and the eastern Atlantic.
\end{abstract}

(C) 2006 Elsevier Ltd. All rights reserved.

Keywords: Sulfur dioxide; Chemical ionization mass spectrometry; Isotopic calibration

\section{Introduction}

Sulfur dioxide $\left(\mathrm{SO}_{2}\right)$ is the predominant anthropogenic sulfur-containing air pollutant. It plays an important role in the atmospheric sulfur cycle through its contribution to acidic aerosol formation, aerosol and cloud droplet modification, and

\footnotetext{
*Corresponding author. Tel.: + 496221516580 ; fax: +496221516324 .

E-mail address: Michael.Speidel@mpi-hd.mpg.de (M. Speidel).
}

acidic precipitation. Due to its large indirect impact on climate it is of interest to precisely know its sources, sinks and its atmospheric distribution. The major natural sources of $\mathrm{SO}_{2}$ in the troposphere are dimethylsulfide (DMS), $\mathrm{CS}_{2}$ and volcanic injection (Seinfeld and Pandis, 1998; Graf et al., 1997). Anthropogenic sources include mainly combustion of sulfur-containing fossil fuels. In the stratosphere $\mathrm{SO}_{2}$ mainly originates from OCS via photo-oxidation but also from direct injection by explosive volcanoes. Within the troposphere $\mathrm{SO}_{2}$ is effectively removed by wet deposition in clouds but also 
reasonably efficient by dry deposition. In the stratosphere $\mathrm{SO}_{2}$ becomes oxidized by the reaction with $\mathrm{OH}$ radicals leading to an average lifetime of about one week, whereas in a $1 \mathrm{~km}$ thick boundary layer the lifetime of $\mathrm{SO}_{2}$ by dry deposition is about one day (Seinfeld and Pandis, 1998).

Measurements of gaseous $\mathrm{SO}_{2}$ mole fractions in the upper troposphere have previously been made using CIMS (chemical ionization mass spectrometry) methods (Möhler and Arnold, 1992; Reiner et al., 1998; Aufmhoff 2003; Thornton et al., 2002) or using gas chromatography/mass spectrometry (Bandy et al.,1993; Gregory et al., 1993). An overview of aircraft-based $\mathrm{SO}_{2}$ measurements in the troposphere is given by Gregory et al. (1993).

The present paper reports on aircraft-borne mass spectrometric measurements of gaseous $\mathrm{SO}_{2}$ using a fast-response ion trap CIMS instrument. Isotopic ${ }^{34} \mathrm{SO}_{2}$ served as an internal calibration standard and was continuously added to the flow tube to achieve high precision and accuracy. The in situ calibration was also used to derive the humidity dependence of the rate coefficient of the major ion molecule reaction (suggested and verified in laboratory experiments by our group (Möhler et al., 1992) to determine gaseous $\mathrm{SO}_{2}$ :

$$
\begin{aligned}
\mathrm{CO}_{3}^{-}\left(\mathrm{H}_{2} \mathrm{O}\right)_{m}+\mathrm{SO}_{2} \rightarrow & \mathrm{SO}_{3}^{-}\left(\mathrm{H}_{2} \mathrm{O}\right)_{p} \\
& +(m-p) \mathrm{H}_{2} \mathrm{O}+\mathrm{CO}_{2} .
\end{aligned}
$$

The effective rate coefficient inferred from the calibration ranges from about $1.0 \times 10^{-9} \mathrm{~cm}^{3} \mathrm{~s}^{-1}$ in dry air to $0.6 \times 10^{-9} \mathrm{~cm}^{3} \mathrm{~s}^{-1}$ in wet air with a maximum of $1.6 \times 10^{-9} \mathrm{~cm}^{3} \mathrm{~s}^{-1}$ in between and is in accordance to previous laboratory observations (Möhler et al. 1992; Seeley et al. 1997). Reaction (1) is followed by the rapid conversion of $\mathrm{SO}_{3}^{-}$ions to $\mathrm{SO}_{5}^{-}$by association of $\mathrm{O}_{2}$ which is available in excess:

$$
\mathrm{SO}_{3}^{-}\left(\mathrm{H}_{2} \mathrm{O}\right)_{n}+\mathrm{O}_{2} \rightarrow \mathrm{SO}_{5}^{-}\left(\mathrm{H}_{2} \mathrm{O}\right)_{m}+(n-m) \mathrm{H}_{2} \mathrm{O} .
$$

We can use the $\mathrm{SO}_{5}^{-}$ion (112 amu or $114 \mathrm{amu}$, respectively) for detection since most hydrates are effectively removed by collisions of $\mathrm{SO}_{5}^{-}\left(\mathrm{H}_{2} \mathrm{O}\right)$ with $\mathrm{He}$ atoms in the ion trap used to confine the ions into the trap center (Gosh, 1995; Keesee and Castleman, 1986). Further, the use of isotopic ${ }^{34} \mathrm{SO}_{2}$ calibration gas allows us to precisely consider wall losses and hydration.
Our modified mass spectrometer instrument is designed specifically for use on aircraft. Thus space and weight requirements are minimized.

\section{Experiment}

An aircraft-based CIMS instrument was used for the present measurements. It consists of the following components: (a) flow reactor (FR), (b) ion source (IS), (c) ion trap mass spectrometer (ITMS), (d) sampling line (SL) and (e) a calibration unit (CU). A commercially available ITMS (Thermo Finnigan Company, Dreieich, Germany) was modified to perform aircraft-based CIMS measurements. The mass spectrometer with its associated vacuum controls, calibration system, and data acquisition is controlled by a PC104+ running Windows 2000 (Microsoft Corp.), software developed using Labview (National Instruments, Austin, TX) and commercial data acquisition software (LCQ, Finnigan Company, Germany). The mass spectrometer is split into three different pressure regimes all separated by critical orifices: The ionmolecule flow reactor holds 39.4 mbar, the focusing unit 3 mbar and the ion trap and detection unit $7.5 \times 10^{-6}$ mbar (Fig. 1). The detection and focusing unit are pumped by a turbomolecular pump and backed by a rotary pump. The ion-molecule flow reactor is pumped by another rotary pump (Alcatel $901428 \mathrm{~V}, 25 \mathrm{~m}^{3} \mathrm{~h}^{-1}$ ). A critical orifice (3.9 mm i.d.) in front of this pump keeps the flow rate through the reactor constant at $8.84 \mathrm{slpm}$ resulting in a residence time in the reactor of $177 \mathrm{~ms}$. A magnetic valve, feedback-operated by a pressure sensor (Wagner Messtechnik, Offenbach, Germany), stabilizes the reactor pressure at 70 mbar. The focusing unit consists of two octapoles separated by a ring electrode. A conversion dynode generates secondary electrons by ion impact, which are concurrently amplified by an electron multiplier and converted into an electric current. The current is digitized by an analog-to-digital converter and finally softwareprocessed.

All ions in the range of $40-180 \mathrm{amu}$ are first trapped together until the trap conditions are automatically changed to sequentially detect one by one the collected ions. Trapping is done in the presence of $\mathrm{He}$, used as a buffer gas to collisionally cool the trapped ions and confine them closer to the trap center and thus increase the efficiency of trapping. Always the same number of ions is injected into the trap, achieved by setting the LCQ 


\section{ITMS}

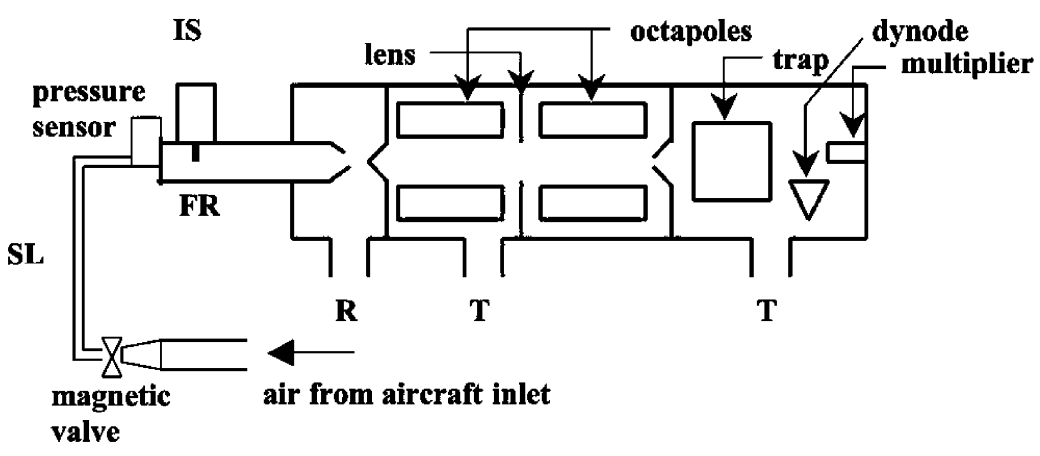

Fig. 1. Schematic cross-section of the mass spectrometer and associated airflow inlet. Each pumping zone is separated by different orifices. The first section was pumped by a $25 \mathrm{~m}^{3} \mathrm{~h}^{-1}$ rotary pump $(R)$. The focusing and detection unit was pumped by a Balzers Pfeiffer TMH $260 / 130$ turbomolecular pump $(T)$ and additionally backed by the rotary pump $(R)$. A magnetic valve feedback operated by a pressure sensor mounted in front of the flow reactor (FR) controls the reactor pressure.

software to automatic gain control (AGC). It automatically increases the ion injection time when the total ion flow into the trap diminishes. In every mass scan the ion current is then automatically scaled by the gain control according to the different ion injection times. The ion injection time itself is determined by a prescan of $0.2 \mathrm{~ms}$ duration. During aircraft experiments signals from 5 mass scans (so-called micro-scans) were obtained by the data acquisition and the resulting average of those scans was stored in the computer. Additionally, LCQ software offers to average over the sum of several obtained mass spectra. The finally achieved average sampling frequency comprised $1 \mathrm{~Hz}$. This resulted in a horizontal resolution of about $200 \mathrm{~m}$ per $\mathrm{SO}_{2}$ data point, considering a typical aircraft speed of $800 \mathrm{~km} \mathrm{~h}^{-1}$ during cruise flights.

In flight ambient air was drawn into the aircraft inlet, developed by DLR. The inlet consisted of a $90^{\circ}$ bent stainless-steel tube, $40 \mathrm{~mm}$ in inner diameter pointing against flight direction. It was permanently kept at a temperature of $20^{\circ} \mathrm{C}$ to avoid icing. Mounted downstream the inlet a further stainless-steel tubing ( $40 \mathrm{~mm}$ i.d.), carried a pressure sensor, a temperature sensor and the inlet of the isotopically labeled internal standard $\left({ }^{34} \mathrm{SO}_{2}\right)$. After about $35 \mathrm{~cm}$ this stainless-steel tubing was connected to a magnetic valve, which on its other side was connected to a $1 \mathrm{~m}$ long PFA (ultrahigh-purity perfluoroalkoxy polymer, Swagelok USA) sampling line (Fig. 1). The inlet for the internal standard also consisted of a stainless-steel tube $(1 \mathrm{~mm}$ i.d.) and was bent $90^{\circ}$ inside the sampling line to point along the main bulk flow, directly toward the magnetic valve. A mass-flow controller $(20$ smlpm, Bronkhorst, The Netherlands) was used to calibrate the flow rate of the internal standard. The PFA sampling line was connected to the ion flow reactor. The reactor is made of stainless steel, $30 \mathrm{~cm}$ in length, and with an inner diameter of $40 \mathrm{~mm}$. A pressure sensor in the reactor duct feedback operates onto the magnetic valve in order to keep the pressure inside the flow-reactor constant (70 mbar). The ion source is mounted on top of the flow reactor to inject the primary reagent ions directly into the reactor. Therefore, an oxygen flow of $0.37 \mathrm{slpm}$ (MFC Bronkhorst, The Netherlands) passes through the high-frequency discharge ion source into the flow reactor. Finally, some fraction of the ion-containing total airstream is directed into the mass spectrometer with its associated ion-beam optics and the detection unit.

The CIMS approach relies upon the conversion of $\mathrm{SO}_{2}$ gas molecules by $\mathrm{CO}_{3}^{-}$ions to $\mathrm{SO}_{5}^{-}$ions (Eq. (1), (2)) (Möhler and Arnold, 1992). We use a high-frequency gas discharge ion source to ionize an oxygen flow (AirLiquide, oxygen 5.0, 150 bar, 2 L) of $0.37 \mathrm{slpm}$ to produce the primary reagent ions $\mathrm{O}^{-}, \mathrm{O}_{2}^{-}$and $\mathrm{O}_{3}^{-}$. The $\mathrm{O}_{3}^{-}$ions are rapidly converted to $\mathrm{CO}_{3}^{-}\left(\mathrm{H}_{2} \mathrm{O}\right)_{n}$ by reaction with $\mathrm{CO}_{2}$ and $\mathrm{H}_{2} \mathrm{O}$. $\mathrm{CO}_{3}^{-}\left(\mathrm{H}_{2} \mathrm{O}\right)_{\mathrm{n}}$ then further reacts with $\mathrm{SO}_{2}$ to form $\mathrm{SO}_{3}^{-}\left(\mathrm{H}_{2} \mathrm{O}\right)_{\mathrm{m}}$ (Eq. (1)) which forms $\mathrm{SO}_{5}^{-}$ion by reaction with excess $\mathrm{O}_{2}$ (Eq. (2)). As mentioned above ${ }^{34} \mathrm{SO}_{2}$ was introduced as calibration gas into the sampling line directly behind the aircraft inlet. Wall losses, mixing and instrument sensitivity are thus almost the same as for atmospheric $\mathrm{SO}_{2}$, which is mostly ${ }^{32} \mathrm{SO}_{2}$. A mass spectrum with a calibration 
peak of 711 parts per trillion by volume (pptv) by use of ultra-dry air and a continuous flow of $8.48 \mathrm{sccm}{ }^{34} \mathrm{SO}_{2}$ is shown in Fig. 2. From the corresponding count rates at mass 112 and $114 \mathrm{amu}$ ambient $\mathrm{SO}_{2}$ mole fractions were computed. The lower limit of detection was experimentally determined to be $22 \mathrm{pptv}$. During these laboratory experiments, synthetic air (Westfalen Gase, Germany) served as gas carrier and signals from 5 mass scans were obtained by the data acquisition and the resulting average of those scans was stored in the computer until 200 averaged scans were completed. Additionally, the pressure in front of the main inlet was varied in steps of 100 mbar ranging from 200 to 900 mbar, simulating different altitudes during flight. For each pressure the arithmetic mean concentration of ${ }^{32} \mathrm{SO}_{2}$ was computed (as described later in this article) from the 200 spectra. No pressure dependence was found and the dew point was below $-60^{\circ} \mathrm{C}$ (capacity sensor, Panametrics). In a second set of experiments the pressure was kept constant at 900 mbar and humidity was changed, by mixing the buffer gas flow with synthetic air, which passed through a bottle filled with purified water. The dew point was varied from $-60{ }^{\circ} \mathrm{C}$ to $+8{ }^{\circ} \mathrm{C}$ by changing the proportion between the dry and humidified airflow. The arithmetic mean concentration of ${ }^{32} \mathrm{SO}_{2}$ was computed for 8 different dew points and from 200 spectra per dew point. The average resulted in $22 \mathrm{pptv}$ with $24 \mathrm{pptv}$ root mean square deviation, independently of the adjusted dew point. Gaussian fitting of the histogram of the calculated ${ }^{32} \mathrm{SO}_{2}$ concentrations resulted in a sigma standard deviation of 19 pptv and was considered as the detection limit.

Another experiment was performed in order to figure out, whether the determined background of $22 \mathrm{pptv}{ }^{32} \mathrm{SO}_{2}$ was related to contamination in the
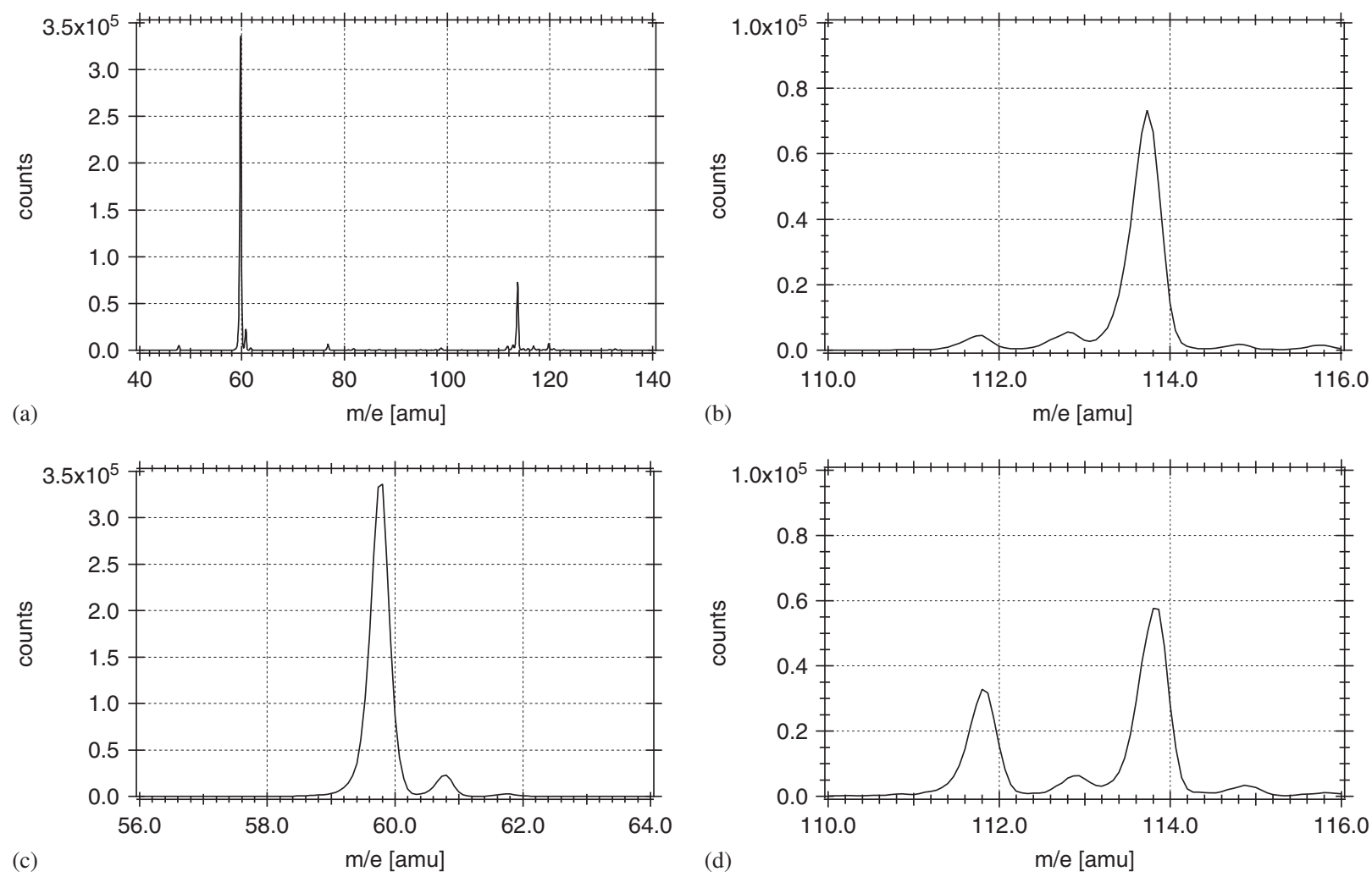

Fig. 2. All shown mass spectra were obtained by sampling synthetic air (dew point below $-60{ }^{\circ} \mathrm{C}$ ). The mass range was adjusted to 40-120 amu. 5 micro-scans with $250 \mathrm{~ms}$ scan time and an average over three spectra were recorded by the data acquisition: Mass spectrum of synthetic air with a $700 \mathrm{pptv}{ }^{34} \mathrm{~S}^{16} \mathrm{O}_{2}$ calibration signal at $114 \mathrm{amu}$ and an $\mathrm{CO}_{3}^{-}$ion peak at $60 \mathrm{amu}$ (a). Isolated $\mathrm{CO}_{3}^{-}$ion peak at 60 amu with a small fraction of $\mathrm{HCO}_{3}^{-}$ions at $61 \mathrm{amu}$ (b). Zoomed view of the ${ }^{34} \mathrm{~S}^{16} \mathrm{O}_{2}$ peak at $114 \mathrm{amu}$ (peak maximum corresponds to 700 pptv). The ${ }^{32} \mathrm{~S}^{16} \mathrm{O}_{2}$ peak appears at 112 amu revealing instrumental background, some ${ }^{32} \mathrm{SO}_{2}$ contamination of the used synthetic air and the ${ }^{32} \mathrm{SO}_{2}$ fraction contained in the calibration gas. (c). Zoomed view of a typical mass spectrum with a calibration gas peak of 711 pptv and an arbitrary ${ }^{32} \mathrm{~S}^{16} \mathrm{O}_{2}$ analyte peak (d). 
buffer gas. The used synthetic air was therefore passed through two filters in series, a charcoal filter and a Purafil filter (Purafil Inc., Atlanta, GA) and the monitored dew point temperature was below $-30{ }^{\circ} \mathrm{C}$. No difference was observed in comparison to the detection limit of $22 \mathrm{pptv}$ as mentioned above.

Fig. 3 gives the calculated precision of a measurement (5 scans averaged) as a function of a given ${ }^{32} \mathrm{SO}_{2}$ mole fraction. Included are inaccuracies due to mass-flow controllers, temperature fluctuations, chemical and isotopic purity of the standard as well as the statistics of the count rate. Above an $\mathrm{SO}_{2}$ level of $100 \mathrm{pptv}$ the relative error in the measured mole fraction is about $12 \%$. For smaller abundances the error increases up to $25 \%$ at the detection limit.

The delivered isotopic ${ }^{34} \mathrm{SO}_{2}$ gas was factory certificated to $650 \mathrm{ppbv} \pm 10 \%$ (Westfalen Gase, Germany). Recalibration in our lab resulted in a mixing ratio of $734 \mathrm{ppbv} \pm 6 \%$. Computation of the ambient $\mathrm{SO}_{2}$ mixing ratios was done taking into account the isotopic purity of the standard as well as the natural isotopic ratio of air. Table 1 shows the used isotopic purities and Eq. (3) gives the relation between isotopic purity, chemical purity of

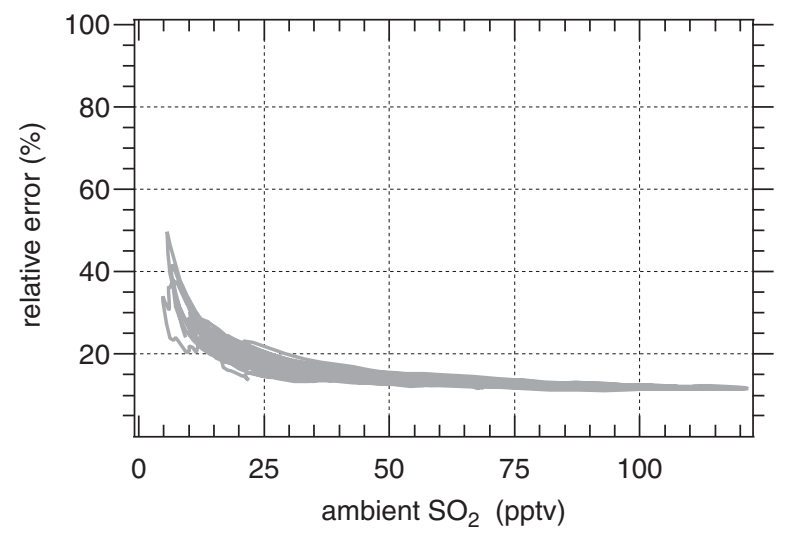

Fig. 3. Relative error per measured data point (5 mass scans) as a function of ambient sulfur dioxide abundances. the standard and derived atmospheric $\mathrm{SO}_{2}$ mole fractions (Bandy et al., 1993),

$C_{\mathrm{a}}=C_{\mathrm{s}} \frac{K_{\mathrm{ss}} R-K_{\mathrm{as}}}{K_{\mathrm{aa}}-K_{\mathrm{sa}} R}$.

$C_{\mathrm{a}}$ refers to the ambient concentration, $C_{\mathrm{s}}$ to the concentration of the standard after injection into the flow reactor and $R$ the ratio of ambient analyte signal counts to isotopic standard signal counts. The $K_{i j}$ values are the relative contributions of the $i$ th species in the $j$ th species and listed in Table 1.

Information about the presence of other species interfering at 112 and $114 \mathrm{amu}$ is given by observing the ratio $112 / 114$ without isotopic calibration. Considering the terrestrial abundances of ${ }^{32} \mathrm{~S},{ }^{34} \mathrm{~S}$, ${ }^{16} \mathrm{O}$, and ${ }^{18} \mathrm{O}$ in nature, one expects the ambient 112 / 114 ratio to be 18.34 . A plot of the experimentally derived ambient abundance ratio $112 / 114$ is shown in Fig. 4. The calculated slope agrees well with the expected ratio.

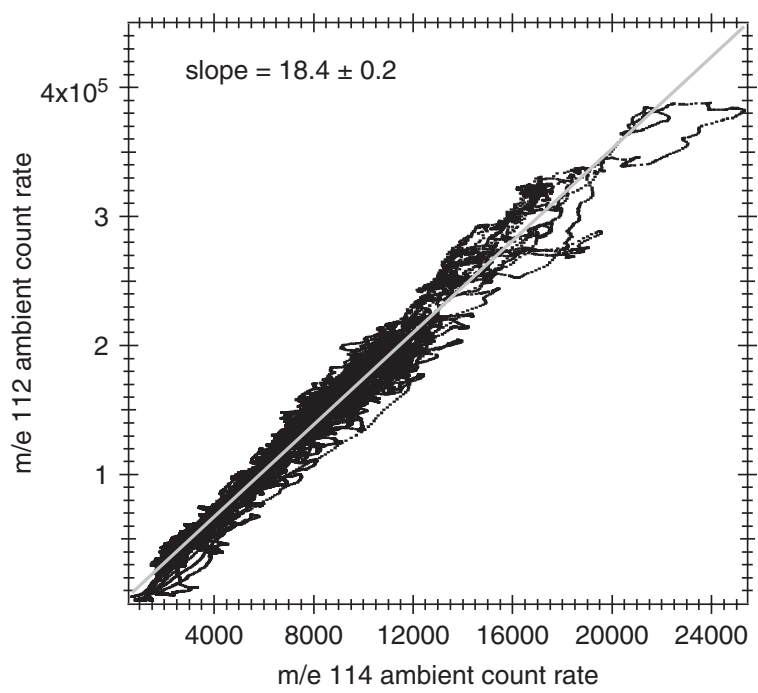

Fig. 4. Signal at $m / e=112 \mathrm{amu}$ as function of the signal at $m / e=114 \mathrm{amu}$ by use of an ambient air flow without isotopic calibration standard. The corresponding slope of a linear fit was computed to be $18.4 \pm 0.2$ (theoretic value: 18.34). For more details see text.

Table 1

Isotopic purity in percentage contribution $\left(K_{i j}\right)$ of the $i$ th compound in the $j$ th species and chemical purity of the standard

\begin{tabular}{llllr}
\hline Species ${ }^{34} \mathrm{~S}^{16} \mathrm{O}_{2}$ and ${ }^{32} \mathrm{~S}^{16} \mathrm{O}_{2}$ & Concentration (ppbv) & $K_{\text {aa }}$ & $K_{\text {ss }}$ & $K_{\text {as }}$ \\
\hline $\begin{array}{l}\text { Standard } \\
\text { Ambient }\end{array}$ & 734 & 0.934 & 0.035
\end{tabular}

The ${ }^{34} \mathrm{SO}_{2}$ concentration of the calibration standard equals $734 \mathrm{ppbv}$. This concentration is diluted by mixing with the total flow to result in a continuous calibration signal of $711 \mathrm{pptv}$. 


\subsection{Model simulations}

To explore the sources of the observed $\mathrm{SO}_{2}$ enhancements, the Lagrangian particle dispersion model FLEXPART (Stohl et al., 1998; Stohl and Thomson, 1999; Stohl et al., 2005) was used. FLEXPART simulates the transport and dispersion of linear tracers by calculating the trajectories of a multitude of particles. The model was driven by global model-level data from the European Centre for Medium-Range Weather Forecasts (ECMWF) with a temporal resolution of $3 \mathrm{~h}$ (analyses at 0,6 , 12, 18 UTC; 3-h forecasts at 3, 9, 15, 21 UTC), a horizontal resolution of $1^{\circ} \times 1^{\circ}$, and 60 vertical levels. Over North America, the North Atlantic and Europe, nested input data with a resolution of $0.36^{\circ} \times 0.36^{\circ}$ were used. Particles were transported both by the resolved winds and by parameterized sub-grid motions. FLEXPART parameterizes turbulence in the boundary layer and in the free troposphere by solving Langevin equations (Stohl and Thomson, 1999) and convection by using the parameterization scheme of Emanuel and ŽivkovićRothman (1999).

Simulations used here were made for passive $\mathrm{SO}_{2}$ tracers with regional origins in Asia, North America and Europe according to the EDGAR emission inventory, except for North America where the high-resolution $(4 \mathrm{~km} \times 4 \mathrm{~km})$ inventory of Frost et al. (2006) was used. The tracers were carried for 20 days and, thus, the results at a particular time indicate the total $\mathrm{SO}_{2}$ emission load received within the last 20 days. Observed $\mathrm{SO}_{2}$ concentrations, which are subject to deposition and chemical conversion, thus, should always be lower than simulated values. The resolution of the output grid in the region of interest was $0.33^{\circ} \times 0.25^{\circ}$; the vertical resolution was better than $500 \mathrm{~m}$ below $6000 \mathrm{~m}$ and $1000 \mathrm{~m}$ above.

\section{Results and discussion}

The described instrumental setup was used within the framework of the ITOP campaign 2004 to obtain $\mathrm{SO}_{2}$ measurements of high accuracy and high temporal resolution. The measurements were carried out above Western Europe and the North Atlantic. All flights were performed on board of the German research aircraft FALCON (DLR). The present data illustrate the accuracy and broad field of application of the instrument.
Here two flights were picked to exemplarily show the reliable performance of the instrument during the ITOP field campaign. The flights comprise the measurement of clean, unpolluted upper tropospheric air from the central Atlantic region, with $\mathrm{SO}_{2}$ abundances close to the instrumental detection limit of 20 pptv and the detection of a lower tropospheric urban pollution plume rich in $\mathrm{SO}_{2}$. Finally, the very short signal of an aircraft contrail is used to gain information about response time and memory effects of the experimental setup.

In Fig. 5 the averaged vertical profiles of the two selected flights are shown covering an altitude range from 0.5 to $10 \mathrm{~km}$. The values scatter between the detection limit of 20 and 2000 pptv, in accordance to earlier measurements (Georgii and Meixner, 1980). The boundary layer in case of FL31 is clearly situated below $2 \mathrm{~km}$ altitude. In case of FL26 several layers of $\mathrm{SO}_{2}$ at different altitudes $(0.6,0.8,1.3,1.5$, 2 and $5 \mathrm{~km}$ ) appear in the vertical profile and probably occur due to wind shearing. The steady decrease of the $\mathrm{SO}_{2}$ concentration up to an altitude of about $5 \mathrm{~km}$ is typical for $\mathrm{SO}_{2}$ and reflects efficient $\mathrm{SO}_{2}$ loss preferably by cloud processes (Thornton et al., 1999).

In the following the $\mathrm{SO}_{2}$ time series are discussed in more detail.

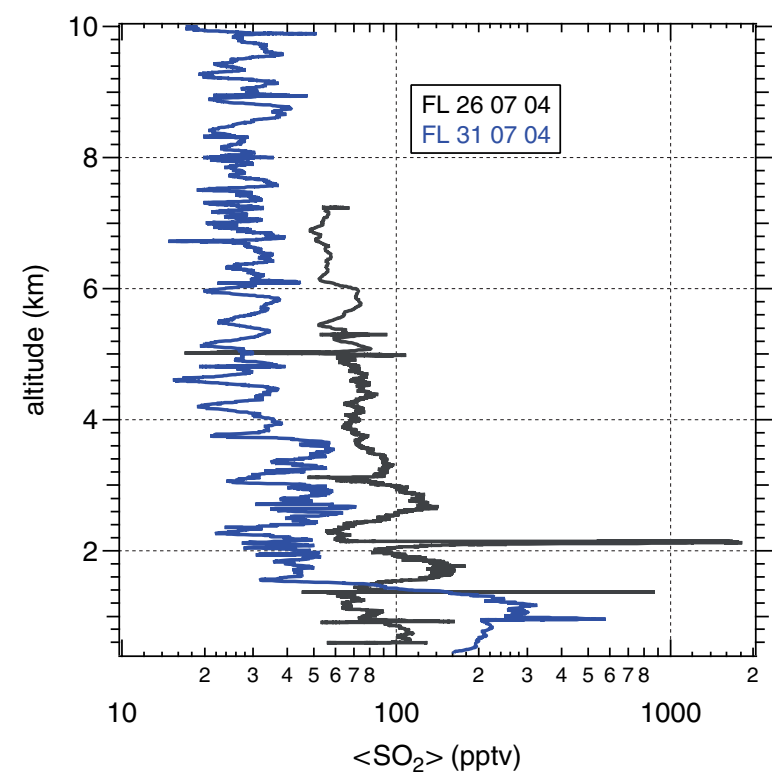

Fig. 5. Vertical $\mathrm{SO}_{2}$ mixing ratios of two ITOP flights performed 26 July and 31 July. For more details see text. 


\subsection{Low level pollution above Western Europe}

During the flight of the 31st of July (FL31) average $\mathrm{SO}_{2}$ abundances of $35 \mathrm{pptv}$ were measured, showing only little variability with altitude between 2.5 and $10.2 \mathrm{~km}$ (Fig. 6a). The boundary layer is clearly marked at an altitude of about $2 \mathrm{~km}$ during ascent (up to $600 \mathrm{pptv} \mathrm{SO}_{2}$ ) and descent (200 pptv $\mathrm{SO}_{2}$ ). The measurements were performed above Northern France with the northernmost position at $51.05^{\circ} \mathrm{N}, 2.71^{\circ} \mathrm{E}$ (close to Lille) and the easternmost position at $49.79^{\circ} \mathrm{N}, 6.21^{\circ} \mathrm{E}$ (Luxembourg). Additionally measured trace gases (CO: $60-80 \mathrm{ppbv}$, $\mathrm{NO}_{x}: 0.2-0.6 \mathrm{ppbv}$ and $\left.\mathrm{NO}_{y}: 0.4-0.8 \mathrm{ppbv}\right)$ indicate weak pollution (Fig. 6a), and the detected $\mathrm{SO}_{2}$ levels are typical of the remote northern hemispheric air at high altitude (Thornton et al., 1999; Tu et al., 2004). A horizontal cross-section of the FLEXPART $\mathrm{SO}_{2}$ total column $\left(\mathrm{mg} \mathrm{m}^{-2}\right)$ from 31 July 2004 at $50400 \mathrm{~s}$ UTC is shown in Fig. 6b. Note that the given time corresponds to the end time of a $2 \mathrm{~h}$ average. A plume centered above the Great Lakes region stretches into the central Atlantic. However, no plume from northern America reached central Europe as indicated by the low total column $\mathrm{SO}_{2}$ levels above Europe. The total column $\mathrm{SO}_{2}$ was below $30 \mathrm{mg} \mathrm{m}^{-2}$ within the flight track (marked in red). Further FLEXPART results not shown here also excluded larger contributions from Asia. The European $\mathrm{SO}_{2}$ is predicted to significantly contribute only at lower altitudes as it was also observed (see Fig. 6a, for UTC $<44000 \mathrm{~s}$ and UTC $>$ 49700 s), whereas the free troposphere was basically not polluted at all by European sources. The FLEXPART results thus well reflect the measured low $\mathrm{SO}_{2}$ mole fractions during FL31.

\subsection{Urban pollution plume}

During the flight of 26 July (FL26) air masses above the English Channel region were sampled. Fig. 7a gives the flight path and corresponding wind vectors. Fig. $7 \mathrm{~b}$ shows the measured $\mathrm{SO}_{2}$ mole fractions as a function of time and the altitude profile. $\mathrm{SO}_{2}$ levels were strongly enhanced (up to $2.5 \mathrm{ppbv}$ ) in the altitude range from $1.4-2.2 \mathrm{~km}$ at 62 960-63790s UTC, with an intermediate minimum at $63217 \mathrm{~s}$ UTC. Within that period the average aircraft speed was $130 \mathrm{~m} \mathrm{~s}^{-1}$ and therefore the horizontal extension of the two plume segments can be estimated to 33 and $74 \mathrm{~km}$, respectively.
At the same time also the $\mathrm{NO}_{y}(\sim 8 \mathrm{ppbv})$ and $\mathrm{NO}$ ( $\sim 2$ ppbv) levels indicated a stronger pollution, accompanied by $\mathrm{CO}$ concentrations rising from 100 to $130 \mathrm{ppbv}$ inside both plume segments. Horizontal and vertical cross-sections through the FLEXPART European CO tracer were used to further characterize the plume. Shown in Fig. 7c is the total column $\left(\mathrm{mg} \mathrm{m}^{-2}\right)$ of the European $\mathrm{CO}$ tracer from 26 July at $64800 \mathrm{~s}$ UTC. Additionally, the vertical cross-section is given between the two points $\left(49.2426^{\circ} \mathrm{N},-3^{\circ} \mathrm{W}\right.$ to $50.969^{\circ} \mathrm{N}, 3^{\circ} \mathrm{E}$ ), also indicated by the black line in the horizontal crosssection. Highest CO levels were distributed around the London region and the plume spread out into southeasterly direction where it became intercepted by the research aircraft. FLEXPART predicted the plume to stay below $2 \mathrm{~km}$ altitude along the vertical cross-section, with the plume center being located at about $1 \mathrm{~km}$ altitude. The Falcon flight path is colorcoded with the measured $\mathrm{SO}_{2}$ mole fraction and the first plume segment at $1.4 \mathrm{~km}$ altitude coincides with the plume interior. The second measured plume segment remains above the predicted maximum plume altitude, indicating somewhat stronger lifting of the plume than simulated by the model, perhaps due to an underestimation of boundary layer heights. However, note that no plume observations were made above $2.2 \mathrm{~km}$, indicating that the plume's vertical extent was quite limited.

\subsection{Response time of the experimental setup}

Due to the difficulties of experimentally generating a temporarily short $\mathrm{SO}_{2}$ signal without the need to consider memory effects intrinsic to signal generation, an observed aircraft contrail served as an opportunity to test the response time of the setup. During the transfer flight on 11 April 2005 from Larnaca to Dubai, which was performed within the SCOUT campaign (Stratospheric-Climate Links with Emphasis on the Upper Troposphere and Lower Stratosphere), an aircraft contrail was coincidentally crossed at an altitude of $10.2 \mathrm{~km}$. Measured $\mathrm{SO}_{2}, \mathrm{NO}$ and $\mathrm{NO}_{y}$ concentrations are shown in Fig. 8, while the contrail was crossed. The $\mathrm{NO}$ and $\mathrm{NO}_{y}$ measurements were performed using a chemiluminescence detector, also implemented on board of the DLR research aircraft Falcon. A data point was taken every second for the $\mathrm{NO}, \mathrm{NO}_{y}$ data, and every $1.14 \mathrm{~s}$ for the $\mathrm{SO}_{2}$ data. The $\mathrm{SO}_{2}$ data were not summed by the LCQ software but averaged over 5 micro-scans. Over a period of $4 \mathrm{~s}$ 

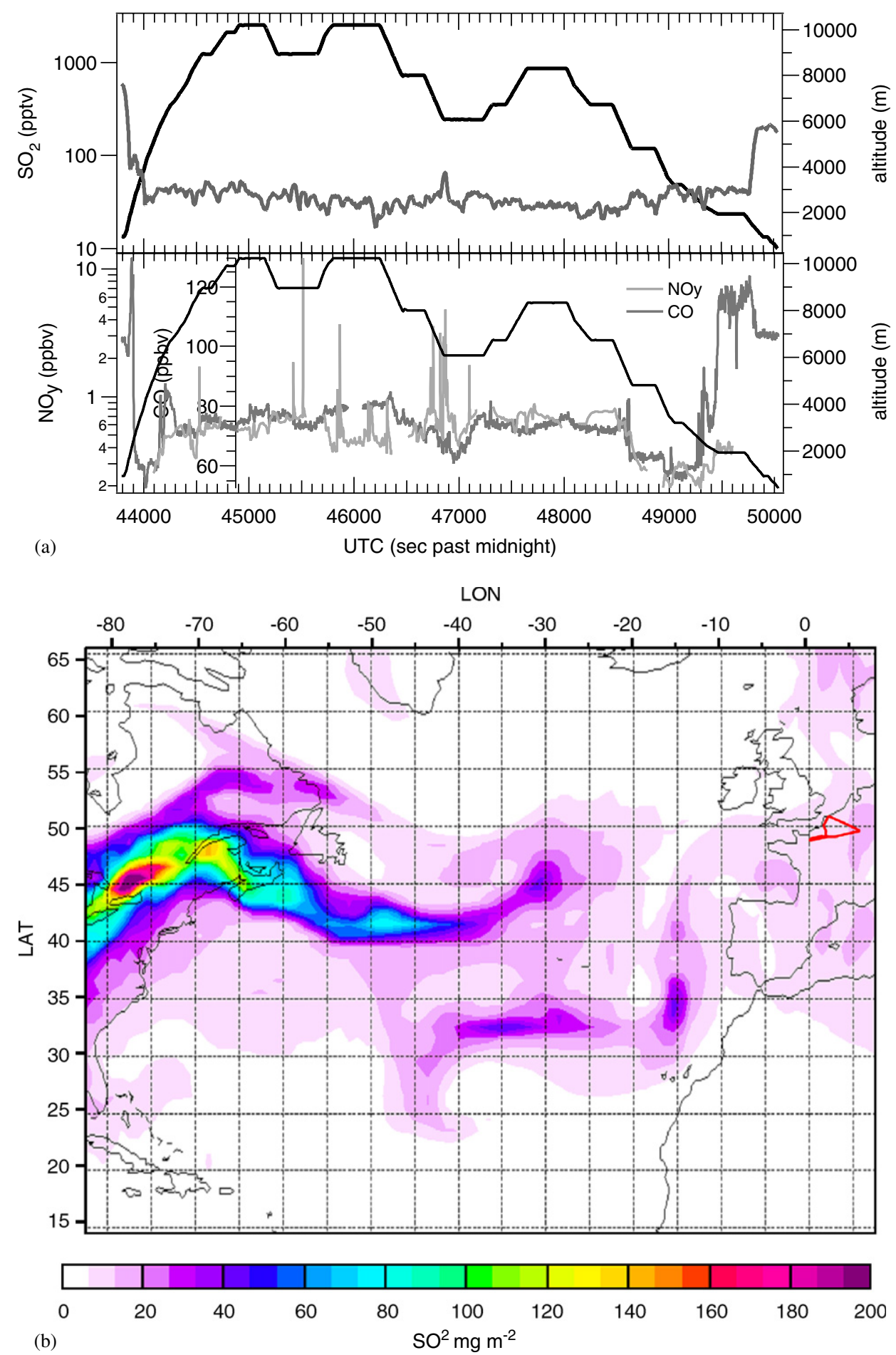

Fig. 6. $\mathrm{SO}_{2}$ time series of the flight performed 31 July (FL31) and altitude profile (black). The average $\mathrm{SO}_{2}$ levels above $6 \mathrm{~km}$ altitude are surprisingly low (35 pptv) and altitude independent (a). Total column of the FLEXPART North American $\mathrm{SO}_{2}$ tracer. The plot represents the average $\mathrm{SO}_{2}$ levels over the last two hours with the endpoint at $50400 \mathrm{~s}$ UTC. The Falcon flight path is marked in red (b). 


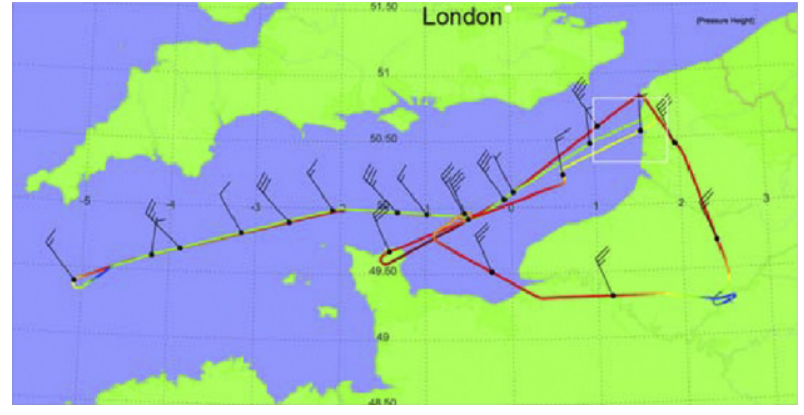

(a)

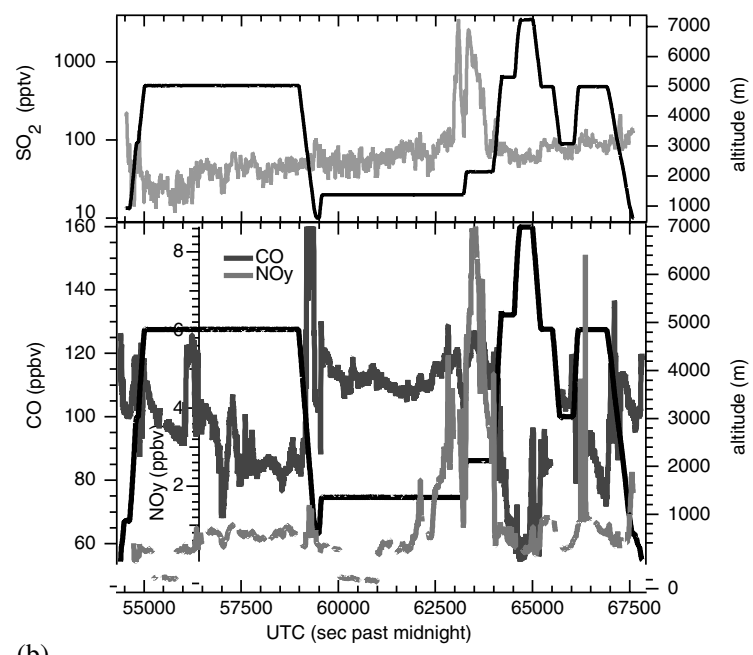

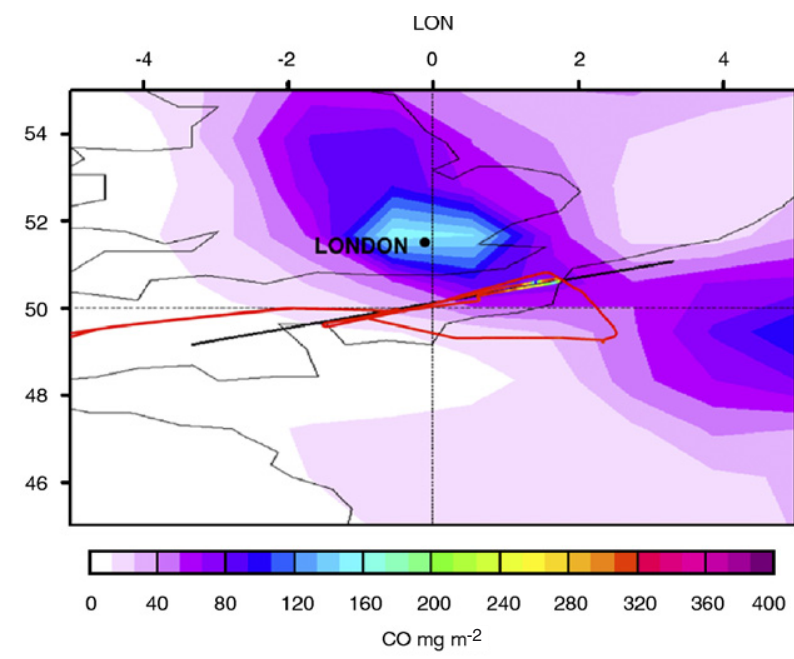

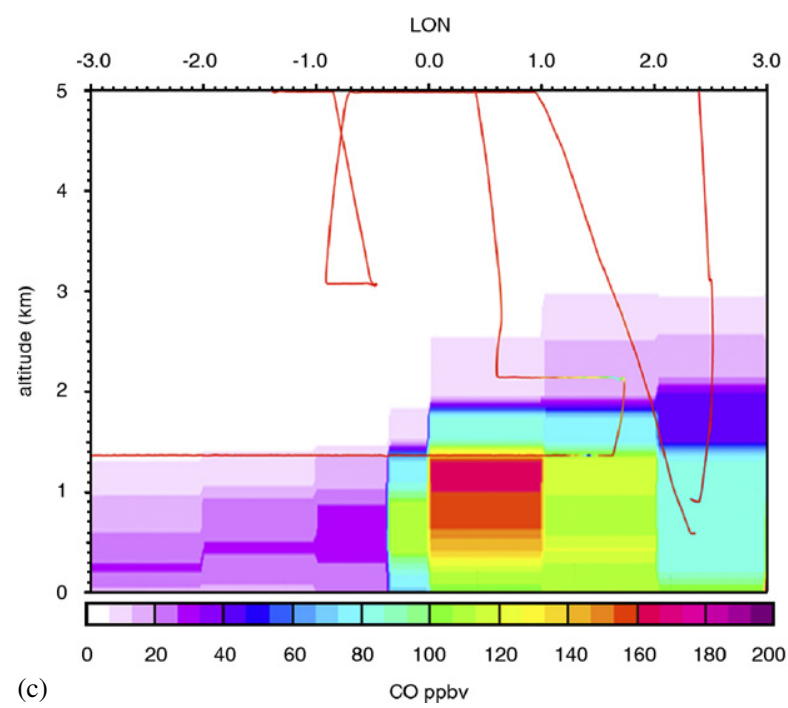

Fig. 7. Map with overlaid flight pattern and wind vectors during 26 July. The area of plume interception with the Falcon aircraft is marked by a gray rectangle (a). $\mathrm{SO}_{2}$ time series of the flight performed 26 July (FL26) and altitude profile (black). Between 62960 and $63790 \mathrm{~s}$ UTC the $\mathrm{SO}_{2}$ level was strongly enhanced (b). Total column of the FLEXPART European CO tracer. The plot represents the average CO levels over the last $2 \mathrm{~h}$ with the endpoint at $64800 \mathrm{~s}$ UTC. The Falcon flight path is color-coded with the measured $\mathrm{SO}_{2}$ mole fraction (c).

the shown trace gases are strongly above the levels measured prior to plume interception $\left(\Delta_{\mathrm{SO}_{2}}=\right.$ $\left.1025 \mathrm{pptv}, \Delta_{\mathrm{NO}}=5.9 \mathrm{ppbv}, \Delta_{\mathrm{NO} y}=7.5 \mathrm{ppbv}\right)$. The large $\mathrm{NO} / \mathrm{NO}_{y}$ ratio confirms that this was a fresh aircraft exhaust plume. The measured $\mathrm{SO}_{2}$ concentrations did not reveal any large memory effects compared to the concurrently measured concentrations of $\mathrm{NO}$ and $\mathrm{NO}_{y}$. From the calculated true airspeed of $221 \mathrm{~m} \mathrm{~s}^{-1}$ during interception, the plume size was estimated to $884 \mathrm{~m}$ and according to Schumann et al. (1998) the plume age was approxi- mated to $74 \mathrm{~s}$ (see also Arnold et al., 1996; Tremmel et al. 1998).

\section{Summary}

Our aircraft-based $\mathrm{SO}_{2}$ measurements made during the ITOP campaign in summer 2004 represent a data set of high resolution (temporal and spatial) and high precision. The latter was achieved by use of isotopically labeled sulfur dioxide $\left({ }^{34} \mathrm{SO}_{2}\right)$ as a calibration gas. 


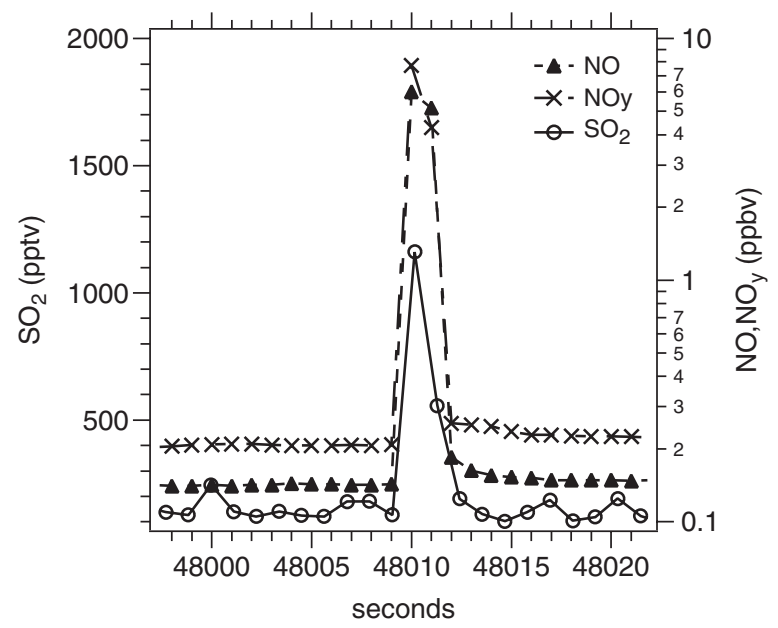

Fig. 8. Detected $\mathrm{SO}_{2}, \mathrm{NO}$ and $\mathrm{NO}_{y}$ levels during crossing of an aircraft contrail. All trace gases are strongly enhanced above atmospheric concentrations measured before interception. For further details see text.

The measurements were performed above Western Europe and cover an altitude range from ground to $12 \mathrm{~km}$.

An urban pollution plume, likely to stem from the London region with $\mathrm{SO}_{2}$ mole fractions of $2.5 \mathrm{ppbv}$ was observed above the English Channel. Surprisingly clean air was observed during the whole flight on 31 July (FL31), with average $\mathrm{SO}_{2}$ mole fractions around $35 \mathrm{pptv}$. The time response of the instrumental setup was checked by use of an aircraft contrail, which was crossed during flight. From the measured $\mathrm{SO}_{2}$ level, the plume age and plume spread were estimated and are in accordance with earlier observations.

\section{References}

Arnold, F., Klemm, M., Schneider, J., Bürger, V., DrosteFranke, B., Kirchner, G., Preissler, B., Jung, A., and Dann, W., 1996. Trace gas measurements by aircraft based ion moelcule reaction mass spectrometry. Report EUR 16978 EN, Luxembourg: Office for Official Publication of the European Communities, pp. 48-69.

Aufmhoff, H., 2003. Atmospheric gaseous precursor of aerosol and ozone: Measurements with CIMS-methods on aircraft and on ground. Ph.D. Thesis, University of Heidelberg.

Bandy, A.R., Thornton, D.C., Driedger, A.R., 1993. Airborne measurements of sulfur dioxide, dimethyl sulfide, carbon disulfide and carbonyl sulfide by isotope dilution gas chromatography mass spectrometry. Journal of Geophysical Research 98, 23423-23433.

Emanuel, K.A., Živković-Rothman, M., 1999. Development and evaluation of a convection scheme for use in climate models. Journal of Atmospheric Science 56, 1766-1782.
Frost, G.J., McKeen, S.A., Trainer, M., Ryerson, T.B., Neuman, J.A., et al., 2006. Effects of changing power plant $\mathrm{NO}_{x}$ emissions on ozone in the eastern United States: proof of concept. Journal of Geophysical Research 111, D12306.

Georgii, H.W., Meixner, F., 1980. Measurement of the tropospheric and stratospheric $\mathrm{SO}_{2}$ distribution. Journal of Geophysical Research 85, 7433-7438.

Gosh, P.K., 1995. Ion Traps. Oxford University Press Inc., New York.

Graf, H.F., Feichter, J., Langmann, B., 1997. Volcanic sulfur emissions: estimates of sources strength and its contribution to the global sulfate distribution. Journal of Geophysical Research 102, 10277-10738.

Gregory, G.L., Davis, D.D., Beltz, N., Bandy, A.R., Ferek, R.J., Thornton, D.C., 1993. An intercomparison of aircraft instrumentation for tropospheric measurements of sulfur dioxide. Journal of Geophysical Research 98, 23325-23352.

Keesee, R.G., Castleman, A.W., 1986. Thermochemical data on gas-phase ion-molecule association and clustering reactions. Journal of Physical Chemistry Reference Data 15, 1011-1071.

Möhler, O., Arnold, F., 1992. Gaseous sulphuric acid and sulfur dioxide measurements in the arctic troposphere and lower stratosphere: Implications for hydroxyl radical abundances. Geophysical Research Letters 19, 1763-1766.

Möhler, O., Reiner, T., Arnold, F., 1992. The formation of $\mathrm{SO}_{5}^{-}$ by gas phase ion-molecule reactions. Journal of Chemical Physics 97 (11).

Reiner, T., Möhler, O., Arnold, A., 1998. Improved atmospheric trace gas measurements with an aircraft-based tandem mass spectrometer: ion identification by mass-selected fragmentation studies. Journal of Geophysical Research 103, 31309-31320.

Schumann, U., Schlager, H., Arnold, F., Baumann, R., Haschberger, P., Klemm, O., 1998. Dilution of aircraft exhaust plumes at cruise altitudes. Atmospheric Environment 32, 3097-3103.

Seeley, J.V., Morris, R.A., Viggiano, A.A., 1997. Rate Constants for the reaction of $\mathrm{CO}_{3}^{-}\left(\mathrm{H}_{2} \mathrm{O}\right)_{n=0-5}+\mathrm{SO}_{2}$ : implications for CIMS detection of $\mathrm{SO}_{2}$. Geophysical Research Letters 24, 1379-1382.

Seinfeld, J.H., Pandis, S.N., 1998. Atmospheric Chemistry and Physics. Wiley, New York.

Stohl, A., Thomson, D.J., 1999. A density correction for Lagrangian particle dispersion models. Boundary-Layer Meteorology 90, 155-167.

Stohl, A., Hittenberger, M., Wotawa, G., 1998. Validation of the Lagrangian particle dispersion model FLEXPART against large scale tracer experiment data. Atmospheric Environment 32, 4245-4264.

Stohl, A., Forster, C., Frank, A., Seibert, P., Wotawa, G., 2005. Technical note: the Lagrangian particle dispersion model FLEXPART version 6.2. Atmospheric Chemistry and Physics 5, 2461-2474.

Thornton, D.C., Bandy, A.R., Blomquist, B.W., Driedger, A.R., Wade, T.P., 1999. Sulfur dioxide distribution over the Pacific Ocean 1991-1996. Journal of Geophysical Research 104, $5845-5854$.

Thornton, D.C., Bandy, A.R., Tu, F.H., Blomquist, B.W., Mitchell, G.M., Nadler, W., 2002. Fast airborne sulfur dioxide measurements by atmospheric pressure ionisation mass spectrometry (APIMS). Journal of Geophysical Research 107 ACH 13:1-10. 
Tremmel, H.G., Schlager, H., Konopka, P., Schulte, P., Arnold, F., Klemm, M., Droste-Franke, B., 1998. Observations and model calculations of jet aircraft exhaust products at cruise altitude and inferred initial $\mathrm{OH}$ emissions. Journal of Geophysical Research 103 (D9), 10803-10816.
Tu, F.H., Thornton, D.C., Bandy, A.R., Carmichael, G.R., Tang, Y., Thornhill, K.L., Sachse, G.W., Blake, D.R., 2004. Long-range transport of sulfur dioxide in the central Pacific. Journal of Geophysical Research 109, D15S08. 